Hydrology and Earth System Sciences, 2(1), 9-18 (1998) C) EGS

\title{
Modelling a river catchment using an electrical circuit analogue
}

\author{
C. G. Collier
}

Telford Institute of Environmental Systems, Dept. of Civil \& Environmental Engineering, University of Salford, Salford M5 4WT, Greater Manchester, United Kingdom

\section{Abstract}

\begin{abstract}
An electrical circuit analogue of a river catchment is described from which is derived an hydrological model of river flow called the River Electrical Water Analogue Research and Development (REWARD) model. The model is based upon an analytic solution to the equation governing the flow of electricity in an inductance-capacitance-resistance (LCR) circuit. An interpretation of $\mathrm{L}, \mathrm{C}$ and $\mathrm{R}$ in terms of catchment parameters and physical processes is proposed, and tested for the River Irwell catchment in northwest England. Hydrograph characteristics evaluated using the model are compared with observed hydrographs, confirming that the modelling approach does provide a reliable framework within which to investigate the impact of variations in model input data.
\end{abstract}

\section{Introduction}

Many successful flood forecasting schemes are based on stochastic approaches which sometimes neglect available information about the physical characteristics of river basins. Deterministic modelling, however, is still not being reliably implemented. In either approach knowledge of basin morphology is difficult to include in operational schemes without significantly increasing the need for additional physical information and calibration.

It is clear that deterministic approaches to flow forecasting can benefit from detailed topographic descriptions of river basins such as Digital Elevation Models (DEM), and from spatially detailed real-time measurements of rainfall as provided by weather radar systems. However, use of these data can be daunting, and some research has adopted simplifying assumptions to reduce the data requirements. For example, Beven and Kirby (1979) introduced the concept of variable saturated areas using a topographic wetness index to define the surface saturated area dynamically. Nevertheless, these conceptual models still require the use of extensive records of historic events to obtain an adequate calibration (Hornberger et al., 1985), and problems still remain in using multi-parameter optimisation or Monte Carlo simulation methods (see for example Freer et al, 1996).
Garrote and Bras (1995) and others have recognised that if physically meaningful parameters are chosen in model formulation, then calibration requirements may be reduced. Likewise, Refsgaard (1997) emphasised the importance of a rigorous and purposeful parameterisation in order to get as few model parameters as possible. Beven (1996) goes further suggesting that the future development of distributed models lies more in developing sub-grid scale parametrisations based directly on large scale measurements rather than on the improvements of the aggregation of small scale theory and parameter values. This suggests that the minimal model to describe the distributed response of a river basin would be simpler than today's distributed models.

The approach to modelling described in this paper is consistent with this view point in that processes are parametrised and linked via a larger scale physical system. In the work to be described the physical system represents the whole basin, and therefore the model adopts a lumped approach, although implementation for individual grid squares can be envisaged.

The aim of the work has been to investigate the possibility of representing the whole of a river basin as an electrical circuit analogue and hence to develop a truly analytical solution to modelling river flow. The extent to which this is achieved will be discussed. 


\section{Conceptualisation of a river catchment as an electrical circuit}

The identification of the analogue between water and electricity is not new. The representation of the flow of water in pipes in terms of an electrical circuit has been described many years ago (see for example Webber, 1971). So to has the analogy between Ohms Law and Darcy's Law for describing the movement of groundwater found a place in standard hydrological textbooks (see for example Shaw, 1994). This analogy has also been used to model crop energy partition and the interaction of the lowest layers of the atmosphere and vegetation with the substrate, usually the soil (see Shuttleworth and Wallace, 1985; Shuttleworth and Gurney, 1990). However, attempts to use this approach to represent river flow do not appear to have been described.

This may be due to the difficulty of associating basin processes with the parameters and responses of an electrical circuit, but it may also be due to the success of the Unit Hydrograph and transfer function approaches to modelling. Unfortunately these approaches mask the physics of catchment processes, and consequently more comprehensive, although not necessarily more successful, physicsbased distributed models have been developed. Distributed models provide a physical framework within which to investigate the impact of, and the sensitivity to, changes in data inputs and catchment characteristics. Unfortunately these impacts are complex, and depend very much upon the ways in which physical processes are represented, much as the performance of atmospheric models depends upon the parameterisations they employ. As mentioned in the previous section there is some disquiet about the ability of current approaches used to formulate such models.

The present work is an attempt to develop an approach to understanding catchment dynamics which would be easy to use quantitatively, verifiable and yet retain the essential physics of catchment processes. A simple analytical model based upon the concept of a inductance-capacitance-resistance alternating current electrical circuit has been developed. However, this has involved making some intuitive assumptions, the validity of which will be considered further. The aim is not to provide an operational flow forecasting model, but rather to provide a framework within which to investigate the impact of changes in model parameters and input data. This approach is somewhat similar to that adopted by Milly and Eagleson (1988), although the analogy and formulation are quite different.

\section{An electrical circuit analogy catchment model}

Hydrological models have been regarded for many years as low-pass filters in that the fluctuations in the river hydrograph are smaller than the temporal fluctuations in the rainfall input. A resistance (R)-inductance (L) electrical circuit is a low-pass filter when an ac voltage is applied in series with the resistance and inductance. A resistancecapacitance (C) circuit is a high-pass filter when the output voltage is measured across the resistance as for the resistance-inductance circuit.

In ac circuits the reactance of capacitors and inductors can be treated much like the resistance of resistors. Hence $1 / \omega \mathrm{C}$, the capacitance reactance, and $\omega \mathrm{L}$, the inductive reactance, where $\omega$ is the frequency of the ac voltage, both determine the magnitude of the current flowing through the circuit.

By analogy, we may regard the current as the river flow; the ac voltage as being related to the rainfall volume; resistance as relating the time it takes for water to pass through the vegetation and along the surface taken as a function of the soil moisture deficit, surface roughness and the soil and the hillslope velocity; capacitance as the water storage and release as evapotranspiration represented by the aerodynamic resistance of the vegetation canopy; and the inductance, a measure of the electric motive force (emf) induced in the circuit as the current changes dependent upon the circuit geometry, as the ratio of the cross-sectional area of the river divided by the velocity of travel down the catchment of the peak flow after rain. Figure 1 shows the processes and the schematic circuit associated with a river basin.

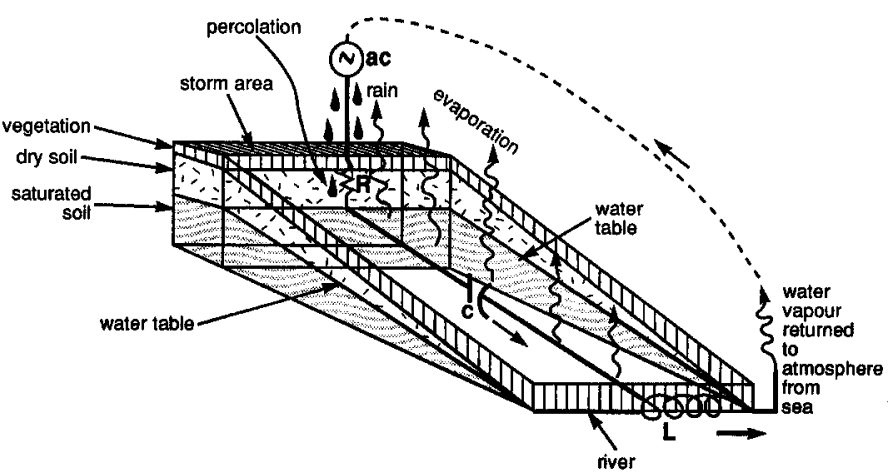

Fig. 1. Schematic representation of river basin processes as an electrical circuit.

\section{Analytical evaluation of river flow}

\section{FORMULATION}

To investigate the impact of changes in frequency of rainfall input, we may use Kirchhoff's emf Law (see for example Reitz and Milford, 1962):

$$
v(t)=R+\frac{c}{C}+L \frac{d I}{d t}
$$

where $v$ is the input voltage (rainfall volume rate time series):

$I$ is the current (river flow); 
$C, R$ and $L$ are as before;

$c$ is the rate of charge of the capacitor taken as the time taken to evaporate the amount of water intercepted by surface vegetation during rainfall.

We may reformulate (1) using dimensional considerations,

$$
r_{v}(t)=\left[R+\frac{c}{C}\right] \cdot \frac{A}{T_{c}}+L \cdot \frac{d q(t)}{d t} \cdot \frac{1}{X}
$$

where

$A=$ cross-sectional area of the river at the bottom of basin

$X=$ mean distance to the nearest water course

$r_{v}(t)=$ rate of rainfall multiplied by the stream area i.e. the rain volume falling on the average catchment area of each individual stream. In what follows we will test the model on the River Irwell basin in North West England. For this river the individual stream area catchment is $1 \mathrm{~km}^{2}$

$q(t)=$ river flow (cumecs)

$T_{c}=$ time of concentration of river

Equation (2) may be solved by assuming that the circuit is suddenly connected to a constant emf, in our case $r_{v}(t)$. The transient response of the circuit takes the form of an exponentially decaying sine wave. Such a response is similar to that reproduced by transfer function flow forecasting models. However, rainfall events are generally not suddenly switched on or off. They are more realistically represented as providing a sinusoidal excitation which carries on for a period of time. Hence, we will assume that $r_{v}$ $(t)$ takes the following form,

$$
r_{v}(t)=r_{m} \sin \omega t
$$

This is a reasonable assumption given the real rainfall time series shown in Fig. 2. Hence substituting (3) in (2) and rearranging the equation then,

$$
\frac{L}{X} \cdot \frac{d q}{d t}=r_{m} \sin \omega t-B k
$$

where

$$
\begin{aligned}
& B=(R+c / C) \\
& k=A / T_{c}
\end{aligned}
$$

Integrating (4) with respect to $t$, assuming that $\omega$ is not a function of $t$ i.e. the application of a rainfall time series having constant frequency gives

$$
\frac{L}{X} \cdot q=-\frac{r_{m}}{\omega} \cos \omega t=B k t+K
$$

where $K$ is a constant
when $t=o, q=q_{b}$, the river baseflow and $K=\frac{L}{X} q_{b}+\frac{r_{m}}{\omega}$

Therefore $q=\frac{r_{m} X}{L . \omega}(1-\cos \omega t)-\frac{B . k . X}{L} . t+q_{b}$
Now $\omega=2 \pi / T_{0}$ where $T_{0}$ is the period of the input rainfall time series, therefore,

$$
q=\frac{r_{m} X T_{0}}{2 \pi L}\left[1-\cos \left[2 \pi \frac{1}{T_{0}}\right]\right]-\frac{B \cdot k \cdot X}{L} \cdot t+q_{b}
$$

This is the basic equation of the REWARD (River Electrical Water Analogue Research and Development) model.

\section{Parameter definition}

We define the $C, L$ and $R$ values as follows:

$$
C=r_{a}
$$

where $r_{a}$ is the vegetation aerodynamic resistance as discussed by Shuttleworth and Gurney (1990) and others. A typical value for an upland grassed area such as the West Pennine Moors of the upper Irwell basin in North West England (see later) is $10^{2} \mathrm{~s} \mathrm{~m}^{-1}$.

$$
L=\frac{\text { cross }- \text { sectional area of river }}{\text { velocity of travel flood peak }}
$$

Taking the River Irwell in North West England as an example and considering a lumped approach, the crosssectional area of the river is taken at the bottom of the catchment (Adelphi Weir, Salford) as about $100 \mathrm{~m}^{2}$. The velocity of travel of the flood peak is taken as approximately the length of the lower part of the river $(20 \mathrm{~km})$ divided by the time of concentration of this part of the river (around 6 hours), namely $1 \mathrm{~m} \mathrm{~s}^{-1}$. Hence $L$ is $10^{2} \mathrm{~ms}$.

The resistance $(R)$ is taken as the characteristic length scale over which a downward pressure force acts. When the ground is saturated rain travels through the vegetation canopy and then moves horizontally along the ground surface. However, when evaporation has dried out the upper layers of the soil rainwater must move downwards through the soil to the water table, the height of which it then modifies.

Both the definition of $R$ and $c$ require more detailed consideration. We relate $R$ to the infiltration of water through the Earth's surface and $c$ to the evaporation of water from the surface. The infiltration process is complicated involving micropores and macropores (see for example Bevan and Germann, 1982, Bronstert and Plate, 1997). The treatment below represents a very simplified view. We deal first with $c$.

The interception of rainfall by vegetation and its subsequent evaporation or drainage through the canopy has been extensively studied (see for example Calder, 1990). The transport of water vapour between the surface and the atmosphere may be estimated using eddy diffusion theory. Hence the flux of water vapour, $F_{w}$, is given by

$$
F_{w}=-\rho_{a} K_{w} \frac{d \bar{r}}{d z} g m^{-2} s^{-1}
$$


where $\rho_{a}=$ air density; $K_{w}=$ eddy diffusion coefficient for water vapour; $\bar{r}=$ specific humidity (approximately the mixing ratio). The vertical gradient of $\bar{r}$ is taken here over the atmospheric boundary layer roughness length, $z_{0}$ (see later).

The amount of water available for evaporation, $\mathrm{W}$, is found from,

$$
W=p_{p} s \mathrm{~g} \cdot \mathrm{m}^{-2}
$$

where $p_{w}=$ density of water; and $s=$ storage capacity of the canopy. Hence,

$$
c=\frac{W}{F_{w}}=-\frac{\rho_{w} s z_{0}}{\rho_{a} \cdot K_{w} \delta \bar{r}}
$$

Taking, $z_{0}=3.9 \mathrm{~cm}$ (see later); $\rho_{p}=1 . \mathrm{g} \mathrm{cm}^{-3} ; \rho_{a}=10^{-3}$ $\mathrm{g} \mathrm{cm}^{-3} ; K_{w}=10^{3} \mathrm{~cm}^{2} \mathrm{~s}^{-1}, s=1 \mathrm{~mm}$ (Calder, 1990 for grass); and $\delta \bar{r}=0.1 \mathrm{~g} \mathrm{~kg}^{-1}$ then $c=-3.9 \mathrm{sec}$. In practice the value of $\mathrm{c}$ will depend upon surface temperature and wind speed as $K_{p}$ and $z_{0}$ will depend on these parameters.

The Distributed Basin Simulator (DBSIM) model developed by Garrote and Bras (1995) assumes that the distributed instantaneous response function of the basin to rainfall is a Dirac delta function with a delay equal to the time of travel from the location of an individual grid element to the outlet of the basin. The travel path for a typical hillslope element consists of a hillslope fraction, corresponding to overland flow or diffuse flow in small gullies, and a stream fraction corresponding to concentrated channelled flow. The hillslope velocity is $v_{h}(t)$ and $v_{s}(t)$ is the stream velocity at time $t$.

Hillslope and stream velocities vary with location, and must be strongly correlated with slope. Therefore a spatial distribution of velocities and hence travel times could be obtained. However, Garrote and Bras (1995) felt that, in the absence of a sound basis to estimate the spatial distribution of velocities, it is appropriate to choose mean velocity values. This is the approach adopted in what follows here. Nevertheless, in general it is necessary to account for some non-linearities in the basin response because travel times are a function of the amount of water present in the basin. Following Garrote and Bras, mean values of hillslope and stream velocities are allowed to vary during a rainfall event and are related as follows,

$$
v_{h}(t)=\frac{v_{s}(t)}{S V}
$$

where $S V$ is the ratio of the stream velocity to hillslope velocity and values of 10-15 have been found to perform well in almost every case.

If the basin response is clearly non-linear then (see for example Pilgrim, 1977),

$$
v_{h}(t)=c c\left|q_{r}(t)\right|^{a}
$$

Where $q_{r}(t)$ is the discharge at the basin outlet at time $t ; a$ is a calibration parameter that controls the degree of non- linearity in the basin; and cc is a calibration coefficient specific to the basin. The best fit values derived for the 840 $\mathrm{km}^{2}$ Arno basin in Italy were found by Garrote and Bras (1995) to be $S V=12.75, c c=0.408 \mathrm{~km} \mathrm{~h}^{-1}$ and $a=0$. Hence $v_{h}(t)=0.408 \mathrm{~km} \mathrm{~h}^{-1}\left(0.1 \mathrm{~m} \mathrm{sec}^{-1}\right)$ and $v_{s}=5.3 \mathrm{~km}$ $\mathrm{h}^{-1}\left(1.3 \mathrm{~m} \mathrm{sec}^{-1}\right)$. However, preliminary studies in the Irwell basin suggest that a is more likely to be around 0.25 for this basin. Following the lumped approach, and taking the once in five year flood for the River Irwell as about 256 cumecs, then from (13) $v_{h}=1.6 \mathrm{~km} \mathrm{~h}^{-1}\left(0.4 \mathrm{~m} \mathrm{sec}^{-1}\right)$ and $v_{s}=21.2 \mathrm{~km} \mathrm{~h}^{-1}\left(5.2 \mathrm{~m} \mathrm{sec}^{-1}\right)$.

Take $F$ as the electrical force due to the movement of electrons, having charge $-e$, along a conductor of length $l$ (see for example Reitz and Milford, 1962) then,

$$
F=e \text {. (potential gradient) }
$$

Taking $E=$ total emf then,

$$
F=d \cdot \frac{E}{l}
$$

Using Ohm's Law,

$$
F=\frac{e}{l} . I . R .
$$

Now assume that $F$ is equivalent to the force causing water to move downwards through vegetation and the soil to the water table (Fig. 1). This force is the rate of transfer across the Earth's surface of momentum along it, $\tau$, the stress arising from the velocity gradient between the movement of water over the surface and the movement of water along the water table. We will assume that this gradient $v$ $(l)=\left(v_{h}+v_{s}\right)$ since the velocity along the water table is usually very much smaller than the surface velocities. The length of the conductor, $l$, is taken as $Z_{0}+\mathrm{SMD}$, where $Z_{0}=$ roughness length of the surface $(m)=0.13 \mathrm{~h}_{\mathrm{v}} ; h_{v}=$ vegetation height $(m)$ (after Choudhury and Monteith, 1988 ); and $S M D=$ soil moisture deficit $(m)$.

This analogue assumes that there is continuity of velocity between the surface and the water table. For areas of a catchment which include water surfaces, impermeable areas, saturated land and areas that saturate rapidly, all water falling produces surface runoff. In such cases this assumption is valid. For other areas where and when the precipitation rate exceeds the infiltration capacity of previously unsaturated soil, the excess is available for the production of overland flow. The overland flow may be accelerated by topographically induced accumulation of lateral moisture flow. Clearly there is no overland flow where there is very little or no rainfall.

The quick transmission of soil water downslope occurs when the macropore system (assumed to be to the depth of tillage or the root zone) has a sufficient degree of connectivity, and when there is significant infiltration into the macropore system due to infiltration excess of the soil matrix at the surface.

As rain water moves down into the soil, the soil water 
content decreases, sometimes quite rapidly for high soil conductivities. This decrease, capillary action in the micropore system and the connectivity of the macropore system, is assumed to provide the continuity of velocity between the surface and the water table. This assumption is taken as valid in significant rainfall situations, but it is conceded that it is unlikely to be valid for groundwater dynamics during periods of little or no rain.

The value of $\tau$ is derived assuming that it has the same form as the stress between the atmosphere and the Earth's surface (see for example Scorer, 1997) namely,

$$
\tau=K . \varsigma . l^{2}\left(\frac{d v}{d Z}\right)^{2}
$$

where $\zeta=$ density of water and $K$ is a constant similar to Von Karman's constant. In the atmosphere $\mathrm{K}$ is equal to about 0.4 . In this case we take $K=Z_{0} / 1$. Therefore, taking the force causing the water to move downwards as the square root of this stress then,

$$
F=\sqrt{\tau}=\sqrt{K \varsigma} . V(l)
$$

Hence, equating (17) and (19) we have,

$$
\frac{e}{l} I . R .=\sqrt{\frac{z_{0}}{l}} \cdot \sqrt{\varsigma} \cdot\left(v_{h}+v_{s}\right)
$$

Therefore,

$$
R=\left(v_{h}+v_{s}\right) \cdot \frac{\sqrt{Z_{0}} \varsigma}{e I} \cdot \sqrt{l}
$$

We assume now that the electron charge multiplied by the current is related to the velocity of the water moving downwards into the soil as a consequence of the hydrostatic pressure, $p$, over the height, $Z_{0}\left(d p / Z_{0}\right)=-\zeta . g$; (see for example Scorer, 1997). The square root of this pressure is taken as the momentum (mass multiplied by the downwards velocity) of the water. Hence,

$$
e I=\sqrt{\text { s.g. } Z_{0}}
$$

where $g=$ acceration due to gravity $\left(\mathrm{m} \mathrm{sec}^{-2}\right)$.

Substitution of (22) in (21) gives

$$
R=\left(v_{h}+v_{s}\right) \cdot \sqrt{\frac{Z_{0}+S M D}{g}}
$$

The resistence $R$ is the characteristic distance over which the additional (to gravity) downwards pressure force, produced by flow over the Earth's surface, acts. This formulation says nothing about how the water actually flows downwards, and is therefore not at variance to the double porous (micropore and macropore) model of infiltration discussed by Bronstert and Plate (1997) and others.

Taking the typical values of $v_{h}$ and $v_{s}$ as above for the Irwell basin as a whole, $h_{v}=0.3 \mathrm{~m}$ and $S M D=0.3 \mathrm{~m}$ then
$R=1.3 \mathrm{~m}$. For a paved drainage basin then $S M D=0$ and $z_{0}$ is redefined in terms of the roughness of the paved area.

We may consider the implications of this approach for the actual depth of water flowing overland. Consider that flow takes place in adjacent 'pathways' each having crosssectional area of $Z_{0} \times 1 \mathrm{~m}^{2}$, then the hillslope flow is $q=v_{h} \times Z_{0}$ cumecs. The depth of water may be derived from $q$ using a discharge-stage relationship (rating curve) and for example with $v_{h}=0.4 \mathrm{~m} \mathrm{sec}^{-1}$ (see eqn. 14) and $Z_{0}=3.9 \mathrm{~cm}$, then the flow is 0.015 cumecs, and the equivalent depth of water is $0.4 \mathrm{~cm}$. As $Z_{0}$ gets larger, then the depth of flow increases, for example for $Z_{0}=1 \mathrm{~m}$ (trees), then $q=0.4$ cumecs equivalent to a flow depth of $2.6 \mathrm{~cm}$, which ignores any interception by trees (Calder, 1990).

This approach has some similarities to that described by Bevan (1997) and others in which $q=r . d a$ where $r=$ steady input rate to the saturated zone and $d a$ is the unit area of the sloping land. However, it should be regarded as a 'parameterisation' of flow overland to small tributary streams. It does seem to give reasonable values, although further testing needs to be undertaken to assess the validity of the approach.

\section{Resonance}

For RLC circuits the current is very small at low frequencies $(\omega \rightarrow 0)$ because the capacitance reactance is great. Similarly, the current is small at high frequencies $(\omega \gg 0)$ because the inductance reactance becomes large. Between these two extremes, the current is a maximum when

$$
\omega L-\frac{1}{\omega C}=0
$$

At this frequency the circuit is said to be in resonance and the peak current is given by Ohm's Law

$$
I_{m}=\frac{V}{R}
$$

where $V$ is the voltage applied to the circuit.

The resonant frequency is

$$
\omega_{0}=2 \pi f_{0}=\frac{2 \pi}{T_{0}}=\frac{1}{\sqrt{L C}}
$$

The ratio of inductive reactance to resistance is called the quality factor, or, more usually, the $Q$ of the circuit. Expressions for the current, I are,

$$
I=\frac{V}{R} \cdot \frac{1}{\sqrt{1+(\omega L / R)^{2}\left(1-1 / \omega^{2} L C\right)^{2}}}
$$

Hence,

$$
\frac{I}{I_{m}}=\left[1+Q_{0}^{2}\left(\frac{\omega}{\omega_{0}}-\frac{\omega_{0}}{\omega}\right)^{2}\right]^{\frac{1}{2}}
$$

where $Q_{0}$ is the value of $Q$ at resonance 

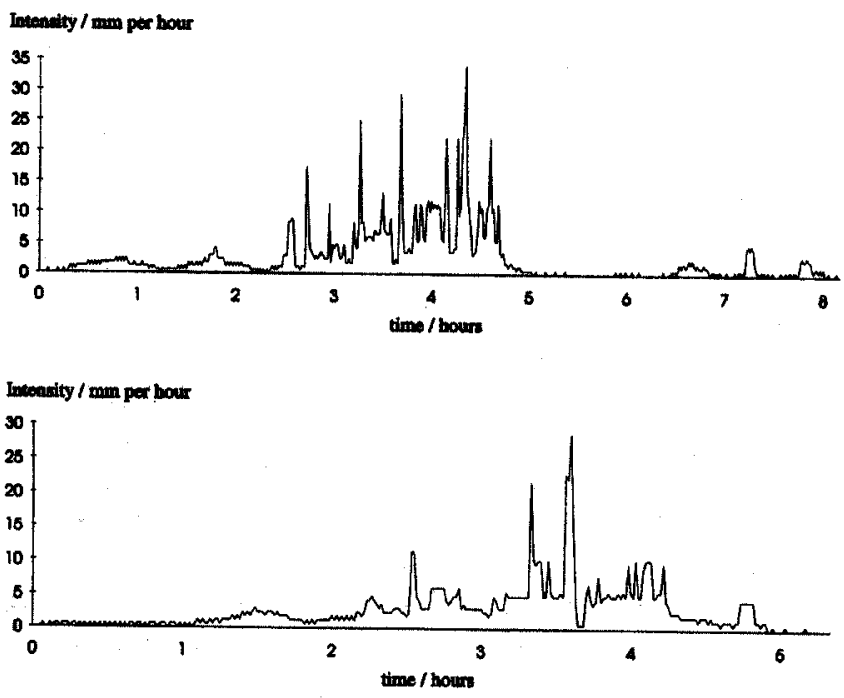

Fig. 2. Plots of fine resolution rainfall (raingauge) data taken from sites in the south-mest of England.

The plots shom intense short-duration rain (convective cells) embedded within lighter long-duration rain (stratiform cells) (from Compertwait et al, 1997).

$$
Q_{0}=\frac{\omega_{0} L}{R}
$$

The $Q$ of the river basin is taken as relating to the shape of the river hydrograph. High $Q$ indicates a peaky hydrograph. Combining (19) and (22) gives,

$$
Q=\sqrt{\frac{L}{C}} \cdot \frac{1}{R}
$$

Plotting the current $I$, corresponding to the river flow, as a function of the frequency of the emf (rainfall time series), curves of the form shown in Fig. 3 may be derived. All the curves shown are based on the same values of $L$ and $C$, but the resistance varies from curve to curve. The curves are sharper for small rather than large values of the resistance. As the driving frequency is varied, not only the

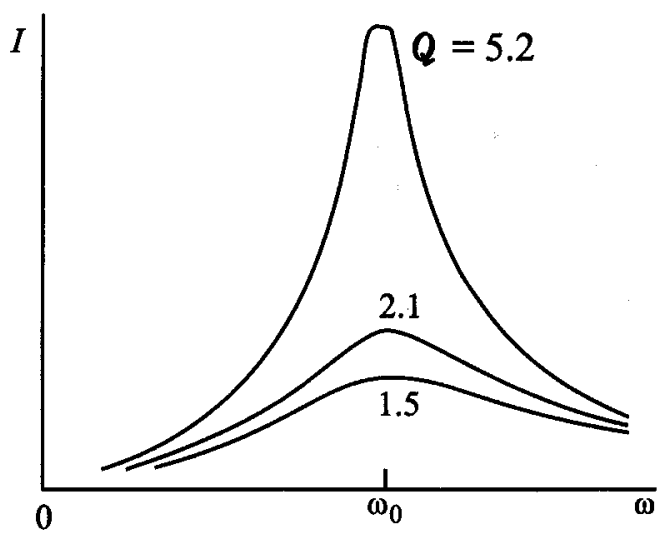

Fig. 3. Resonance curves for a series $R-L-C$ circuit. magnitude, but also the phase, of the current (flow) varies. Below resonance, the phase of the current (flow) is positive and it leads the voltage (rainfall). Above resonance, the opposite is true, and the current (flow) lags the voltage (rainfall).

For the Irwell Basin, using the values of $L, C$ and $R$ given in the previous section, the $Q$ is about $0.8, \omega_{0}=10^{-2}$ $\mathrm{sec}^{-1}$ and $T_{0}$ about ten minutes. This is the period (frequency) of the input rainfall time series which will produce the maximum river flow from each unit of rainfall throughout the event. Periods (frequencies) other than this value will reduce the peak flow from the maximum possible from the amount of rain falling on the basin area as shown in Figure 4.

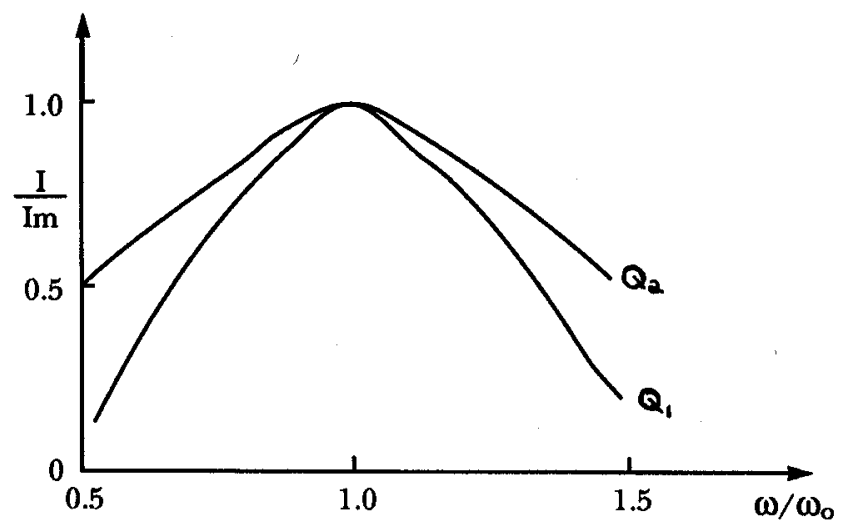

Fig. 4. Shape of the flow/peak flow $\left(I / I_{m}\right)$ function as a function of $\omega / \omega_{0}$.

\section{Applications to the River Irwell basin}

The River Irwell is a tributary of the River Mersey in north west England (Fig. 5). Using (7) and the parameter values discussed previously we may evaluate the river flow resulting from specific rainfall input. Hence taking: $T_{0}=$ 20 minutes; $A=100 \mathrm{~m}^{2} ; X=100 \mathrm{~m}$ (the mean number of stream junctions recorded on a $1: 25000$ map in the upper Irwell basin is approximately 1 per $\mathrm{km}^{2}$, and therefore this value of $X$ is not unreasonable); $L=10^{2} \mathrm{~m} \mathrm{sec} ; B=R+$ $c / C=1 \mathrm{~m} ; T_{c}=6$ hours; $k=5.10^{-3} \mathrm{~m}^{2} \mathrm{sec}^{-1}$ and $\mathrm{r}_{\mathrm{m}}=$ $1 \mathrm{mmh}^{-1} \times 1 \mathrm{~km}^{2}$, the maximum rain volume. The value of $r_{m}$ is equivalent to a storm rainfall of $40 \mathrm{~mm}$ in 4 hours over $10 \mathrm{~km}^{2}$. The river flow time series obtained is shown in Fig. 6 which has a peak flow of 64 cumecs above the base flow.

In deriving (7) the rainfall was assumed to provide a sinusoidal excitation of constant amplitude to the 'circuit', which carried on for a period of time. This assumption is a reasonable first order approximation for a rainfall time series. However, in reality, the 'circuit' is subjected to a series of impulses (IMP) of variable amplitude as shown in 


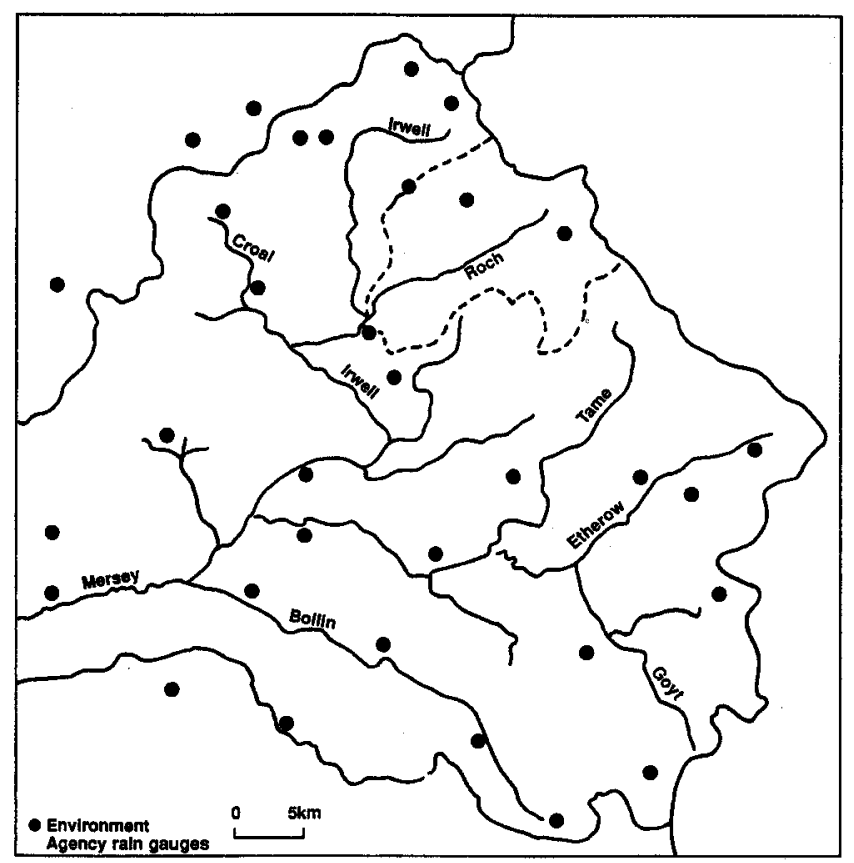

Fig. 5. River Irwell basin in north west England. The dashed line shoms the size of a typical subcatchment

Fig. 2. These impulses may have different time dependent frequencies. Unfortunately (7) is not amenable to analytical solution when $\omega=\omega(t)$.

However, the resultant river flow may be found by adding together the set of impulse responses corresponding to the rainfall time series, that is,

$$
q(t)=\Sigma G\left(t-t^{\prime}\right) \mathrm{IMP}+\text { transient }
$$

where the function $G\left(t-t^{\prime}\right)$ is called the Green's function (see for example Kibble, 1966). This function represents the response of the 'circuit' to the impact of unit impulse delivered at the time $t^{\prime}$. Hence the net effect of a rainfall time series (Fig. 2) is assumed to be the sum of a number of functional solutions such as that shown in Fig. 6. In practice we take the envelope of this function in order to construct a physically realistic functional response to the total storm rainfall over the average tributary stream catchment area. This is similar to the selection of a physically realistic transfer function.

Hence taking the positive envelope of the function in Fig. 6 (shown as a dashed line) we see that the river rises to its peak flow at $0.25 T_{0}$, and recedes much more slowly over a time interval of about $19 T_{0}$, where $T_{0}$, is the period of the input rainfall time series.

Figure 7 shows the hydrograph for a minor event, the like of which occurs many times per year. The peak flow is about 8 cumecs. In this case, the storm rainfall is about $17 \mathrm{~mm}$ in 12 hours over $120 \mathrm{~km}^{2}$ that is $r_{m}=0.01 \mathrm{mmh}^{-1}$ $\times 1 \mathrm{~km}^{2}$. The hydrograph derived using (7) is shown as a dashed line. The value of $T_{0}$ is about five hours. Therefore (7) suggests that the river should rise to its peak in about 1.25 hours, and take about 47 hours ( 2 days) to recede

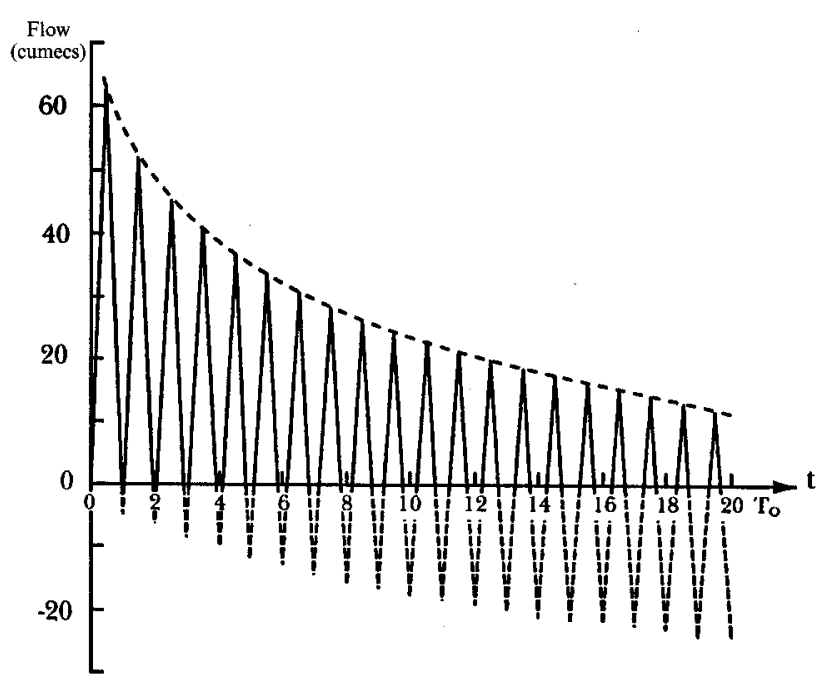

Fig. 6. Evaluation of functional expression for the flow of the River Irwell at the bottom of the basin (Adelphi Weir, Salford).

fully. Figure 7 shows that, in fact, the river takes about 12 hours to rise to its peak, although it rises to about $80 \%$ of the peak flow in about 3 hours. The river is seen to fall to its base level after about 2 days.

Equation (7) shows that the magnitude of the peak flow is closely related to the rainfall input as one would expect. The peak flow occurs when $t=T_{0} / 4$ and is,

$$
q_{p}=\frac{T_{0} . X}{2 . L}\left(\frac{r_{m}}{\pi}-\frac{B . k}{2}\right)+q_{b}
$$

For a rainfall of $160 \mathrm{~mm}$ in 2 hours over $10 \mathrm{~km}^{2}\left(r_{m}=\right.$ $\left.8 \mathrm{mmh}^{-1} \times 1 \mathrm{~km}^{2}\right)(32)$ gives a value for the peak flow of 532 cumecs above the base flow. Such a rainfall is comparable to the rainfall totals from the Hampstead (southern England) storm on 14 August 1975, $170 \mathrm{~mm}$ in 2.5 hours, and the $193 \mathrm{~mm}$ (approximately) in 2 hours from the Halifax (northern England) storm on 19 May 1989.

This calculated peak flow for the River Irwell may also be compared to the flows predicted at Adelphi Weir at the bottom of the basin by the UK Flood Studies rainfallrunoff model (FSR 1975) listed in Table 1. In addition, the highest ever flow recorded for this river is $\mathbf{5 8 5}$ cumecs which occurred on 20 September 1954. Note that (32) is consistent with the expectation that the peak flow on any occasion will decrease as the resistance increases i.e. as the SMD increases.

The base width of the hydrograph depends in a complex way upon the value of $T_{0}$. To compare the observed base width, $T_{B}$, defined as the time difference between the event start and the point when the flow reaches $1 / e$ of the peak flow, with the value derived from (7) (Fig. 6), we have analysed a number of hydrographs measured at the bottom of the Irwell basin. This comparison is shown in Fig. 8, in which the error bars give an indication of the uncertainties in both the extraction of the base length 
Table 1. Flows at Adelphi Weir, Salford predicted using the FSR

\begin{tabular}{cc}
\hline $\begin{array}{c}\text { Return period } \\
\text { (years) }\end{array}$ & $\begin{array}{c}\text { Peak Flow Values } \\
\text { (cumecs) }\end{array}$ \\
\hline 10 & 341.19 \\
50 & 474.40 \\
100 & 550.36 \\
200 & 638.34 \\
500 & 780.25 \\
\hline
\end{tabular}

(width) of the hydrograph and the derivation of $T_{0}$ from the rainfall time series by frequency analysis methods. The extraction of the dominant frequency from the rainfall time series is not straightforward, and is the subject of continuing research.

Also shown in Fig. 8 is the base length of the hydrograph derived empirically and used for some years, that is $T_{B}=2.52 . T_{c}$ where $T_{c}=$ time of concentration of the river. It would appear that the observed values of $T_{B}$ fit the theory quite well. The empirical value of $T_{B}$, however, does seem to be consistent with an overall mean as one might expect.

\section{Sensitivity to input rainfall frequency}

The frequency of the input time series will depend upon the base time period (sampling interval) of the rainfall used. For example, a raingauge network may supply data at 15 minute intervals, and a radar system at 5 minute intervals or less. The dominant frequency depends upon the time step used to define the time series. Large time steps will introduce significant aliasing effects which mask

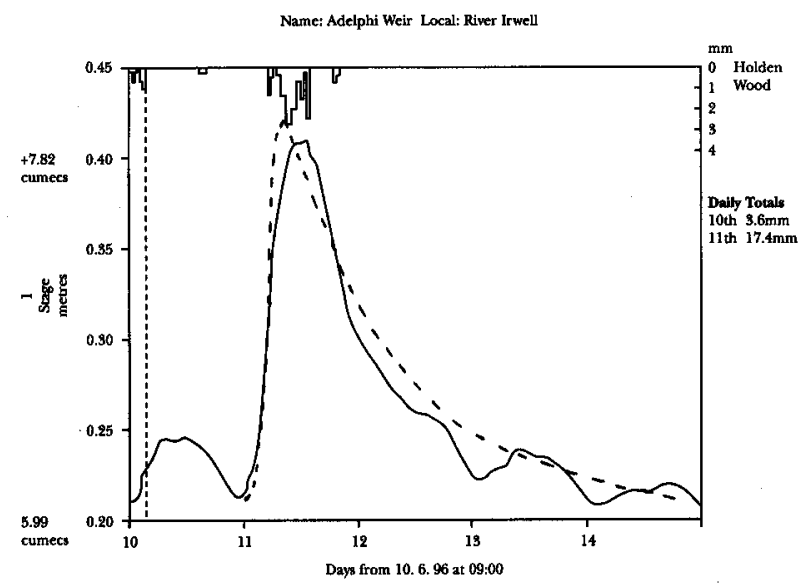

Fig. 7. Example of hydrograph for the River Iropell generated by stratiform rainfall. The solid line is the observed hydrograph and the dashed line is that estimated using (7).

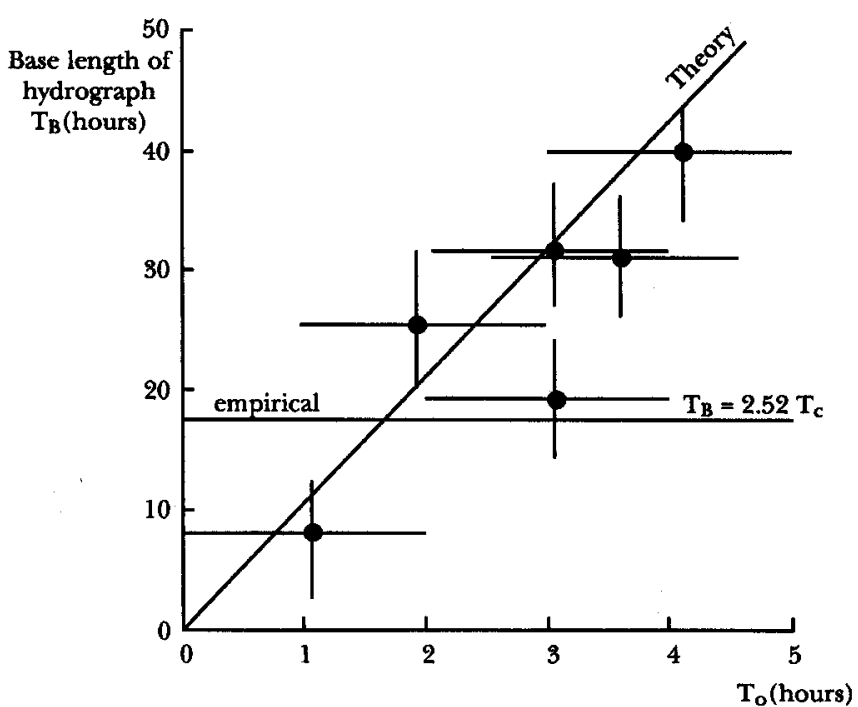

Fig. 8. Width of the hydrograph for the River Irpell as a function of the period (inverse frequency) of the rainfall time series from theory (full line), observation (dots) and as derived empirically and used operationally.

higher frequencies in the time series. In a transfer function approach to modelling this is equivalent to the shape of the transfer function changing with the time step. In the approach outlined in this paper, the way in which the width and peak flow of the hydrograph relate to changes in the frequency may be quantified by (7) and (32). The changes will also depend upon the temporal dependence of the error characteristics of these data, and the dynamics of the rainfall system producing the rain. Figure 2 shows examples of an actual rainfall time series using a sampling interval of one minute for both convective and stratiform rainfall. The time period of the stratiform rainfall is about one hour, and that of convective rainfall about 20 minutes.

The frequencies of both stratiform and convective rainfall may be changed by errors in the technique used to measure such rainfall. For bright-band situations, the region where snow melts to form rain, see for example Collier (1996), a radar may overestimate the rainfall when the radar beam intersects the bright-band. This will introduce higher frequencies into the rainfall time series moving the 'catchment circuit' towards its resonant value for which the river peak flow will be a maximum for the storm rainfall total input. However, if the frequency moves through and beyond the resonant value, then the peak flow will again decrease. In convective rainfall, the presence of hail in the radar beam will increase rainfall frequencies, whereas the occurrence of radar beam attenuation may lead to input rainfall rates which may appear as approximately a square wave.

Many frequency components are present in a square wave. If a rainfall time series having the form of a square wave is applied to a hydrometerological $R C$ circuit, the output waveform, the hydrograph, becomes a series of 
attenuating positive and negative sharp pulses. This is consistent with the approach to catchment modelling known as transfer function modelling. Correspondingly by taking the output voltage across the capacitor the circuit performs the operation of integration producing a triangular waveform form from the square wave input. This situation resembles that of a unit hydrograph type of model. The RC part of the circuit might be regarded as the rainfall-runoff model, and the inductance as the routing model. The higher frequencies present in a square wave are necessary in order to reproduce the sharp corners of the square wave. Likewise, the high frequency terms must be included in order to obtain the sharp corner of a sawtooth waveform. Removal of higher frequencies will smooth the hydrograph, whereas addition of higher frequencies will make the hydrograph more peaky. Hence, the frequency structure of the rainfall time series has as much impact upon the shape of the river hydrograph as the storm total rainfall.

\section{Concluding remarks}

The use of an electrical circuit analogue to represent a river basin provides a mathematical equation relating river flow to rainfall and basin characteristics. This approach has been tested successfully for the river Irwell basin in north west England.

Whilst the peak flow of a river is directly related to the storm rainfall volume over the average area of tributary streams, rainfall frequency and antecedent conditions through $R$ and $c$, the shape of the river hydrograph depends mainly upon the frequency of the input rainfall time series. High frequencies arising in convective rainfall cause peaky hydrographs as observed.

This approach to basin modelling does not require model calibration, although it does require continuous information on catchment characteristics such as soil moisture and vegetation. It is therefore a deterministic approach to flow forecasting. However, its possible success in an operational environment is not clear. The original motivation for this work was to provide a framework for the testing of the impact upon the hydrograph of errors in rainfall input arising from measurement techniques particularly radar. Future work will investigate this further. However, it is already clear that errors which modify the frequency as well as magnitude of the input are significant in that they change the shape of the river hydrograph in a non-linear way. Also modification of the frequency structure of the input time series may restrict the applicability of particular types of hydrological model at specific times. However, further work is necessary to confirm or refute this possibility.

Finally, in this paper we have considered a lumped approach to catchment modelling. It is possible to develop the model in terms of a network of linked LCR circuits to provide a distributed structure. It remains unclear whether this would be successful and further work is necessary to explore its feasibility.

\section{References}

Beven, K.J. (1996) 'A discussion of distributed hydrological modelling', Chapter 13A in Distributed Hydrological Modelling, editor M.B. Abbott and J.C. Refsgaard, Kluwer Acad. Publ., Dordrecht, 255-278.

Beven, K.J. (1997) 'Process, heterogeneity and scale in modelling soil moisture fluxes', in Nato ASI Series, Vol 46 Land Surface Processes in Hydrology. Trials and Tribulations of Modelling and Measuring, editors S. Sorooshian, H.V. Gupta and J.C. Rodda, 191-213.

Beven, K.J. and Kirby, M.J. (1978) 'A physically-based, variable contributing area model of basin hydrology', Hydrol Sci.Bull, $24,43-69$.

Beven, K.J. and Germann, P.F. (1982). 'Macropores and water flow in soils', Wat. Resour. Res., 18, 1311-1325.

Bronstert, A. and Plate, E.J. (1997). 'Modelling of runoff generation and soil moisture dynamics for hillslopes and microcatchments', 7. Hydrol. 198, 177-195.

Calder, I.R. (1990). Evaporation in the Uplands, Wiley, 148pp.

Choudhury, B.J. and Monteith, J.L. (1988). 'A four-layer model for the heat budget of homogeneous land surfaces, Quart. 7.R. Meteorol Soc., 114, 373-398.

Collier, C.G.(1996). Applications of Weather Radar Systems. A guide to uses of radar data in meteorology and hydrology, Wiley-Praxis, Chichester, $390 \mathrm{pp}$.

Cowpertwait, P.S.P. and O'Connell, P.E. (1997). 'A regionalised Neyman-Scott model of rainfall with convective and stratiform cells', Hydrol. Earth System Sci. 1, 71-80.

Freer, J., Ambroise, B. and Beven, K.J. (1996). 'Bayesion estimation of uncertainty in run off prediction and the value of data: an application of the GLUE approach', Wat. Resour. Res. 32, 2161-2173.

FSR (1975) Flood Studies Report, NERC.

Garrote, L and Bras, R.L. (1995). 'A distributed model for realtime flood forecasting using digital elevation models', J. Hydrol., 167, 279-306.

Hornberger, G.M., Beven, K.J., Cosby, B.J. and Sappington, D.E. (1985). 'Shenandoah Watershed Study: Calibration of a topography-based variable contributing area hydrological model to a small watershed', Wat. Resour. Res., 21, 1841-1850.

Kibble, T.W.B. (1966). Classical Mechanics, McGraw-Hill, London, $296 \mathrm{pp}$.

Milly, P.C.D. and Eagleson, P.S. (1988). 'Effect of storm scale on surface runoff - volume', Wat. Resour. Res., 24, 620-624.

Reitz, J.R. and Milford, F.J. (1962). Foundations of Electromagentic Theory, Addison-Wesley, Reading, Mass., USA, $387 \mathrm{pp}$.

Refsgaard, J.C. (1997). 'Parameterisation, calibration and validation of distributed hydrological models', f. Hydrol., 198, 69-97.

Scorer, R.S. (1997). Dynamics of Meteorology and Climate, Praxis Publishing, Wiley, Chichester, U.K. 686 pp.

Shaw, E.M. (1994). Hydrology in Practice, 3rd Edition, Chapman and Hall, London, U.K. 569pp.

Shuttleworth, W.J. and Gurney, R.J. (1990). 'The theoretical relationship between foliage temperature and canopy resistance in sparse crops', Quart, 7.R. Meteorol. Soc., 116, 487-519. 
Shuttleworth, W.J. and Wallace, J.S. (1985). 'Evaporation from sparse crops - an energy combination theory', Quart. 7.R. Meteorol. Soc., 111, 839-855.

Webber, N.B. (1971). Fluid Mechanics for Civil Engineers, Chapman and Hall, London, U.K. 373-398.

\section{Acknowledgement}

This work was carried out as part of the DARTH (Development of Advanced Radar Technology for application to Hydrometeorology) Project (ENV4-CT96-0261) funded by the European Union Framework IV Programme through the UK Meteorological Office. Thanks are also due to Dr P J Hardaker for his encouragement: The help of the Environment Agency (North West Region) via the provision of raingauge and river flow data is gratefully acknowledged. The arguments in support of the analogue put forward in this paper have significantly benefited from the challenging comments made by one of the unnamed reviewers.

\section{Appendix A}

\author{
GLOSSARY OF TERMS \\ $A$ cross sectional area of river at bottom of basin \\ $B \quad(R+c / C)$ \\ $c$ time taken to evaporate the amount of water intere- \\ cepted by surface vegetation during rainfall \\ $C$ vegetation aerodynamic resistance \\ $F \quad$ Force causing water to move downwards into the soil \\ $F_{p}$ flux of water vapour \\ $g \quad$ acceleration due to gravity
}

$h_{v} \quad$ vegetation height

$k \quad \mathrm{~A} / \mathrm{T}_{\mathrm{c}}$

$K \quad$ Von Karman's constant, $Z_{0} / l$

$K_{\mathfrak{m}} \quad$ eddy diffusion coefficient of water vapour

$l \quad\left(Z_{0}+S M D\right)$

$L \quad A /$ velocity of travel of flood peak

$p \quad$ hydrostatic pressure

$q_{b} \quad$ base flow of river

$q_{p} \quad$ peak flow of river

$q(t) \quad$ river flow as function of time

$r_{a}$ surface aerodynamic resistance

$r_{m} \quad$ peak rainfall volume over average tributary stream catchment area

$r_{v} \quad$ rainfall volume over average tributary stream catchment area

$R \quad\left(v_{h}+v_{s}\right) / \sqrt{\left(z_{0}+S M D\right) / g}$; characteristic distance over which downwards pressure force acts

$s \quad$ storage capacity of vegetation canopy

$S M D$ soil moisture deficit

$S V$ ratio of stream velocity to hillslope velocity

$\tau \quad$ water stress

$t$ time

$T_{c} \quad$ time of concentration of river

$T_{0} \quad$ period of rainfall volume time series

$v_{h} \quad$ hillslope velocity

$v_{s} \quad$ stream velocity

$W$ amount of water available for evaporation

$\omega$ frequency of rainfall volume input $2 \pi / T_{0}$

$\mathrm{X}$ mean distance to nearest water course

$z_{0} \quad$ roughness length of the surface $\left(0.13 \mathrm{~h}_{\mathrm{v}}\right)$ 